\title{
Service Learning: A Proposal for the Maker Approach
}

\author{
Irene Frazzarin and Danila Leonori
}

\begin{abstract}
Education plays a vital role in promoting the acquisition of 21 st-century skills. This is why it is important to implement a social intervention project in which makers and technology are key to the learning process, and students can come together to deal with issues within their community.
\end{abstract}

Keywords Service learning $\cdot$ Learning by doing $\cdot$ Project-based learning $\cdot$ Maker approach $\cdot$ Coding $\cdot$ Digital storytelling

Education plays a vital role in promoting the acquisition of 21 st-century skills. However the "pedagogical methods many educational programmes use today primarily serve a standardised, industrial, content-delivery-and-reproduction model, with little or no room for learners to acquire or demonstrate skills beyond content knowledge. This has meant that such systems have increasingly diverged from the needs of those being educated, today's society, and the current global economic system" [1]. This is the reason why a school's physical position in the community is crucial. The reality is that there is often no connection between it and the classroom, the very place where knowledge is taught: access is now far more widespread than ever before, thanks to the extensive availability of technological resources. We teachers and the children in our schools are witnessing a significant rise in social inequalities, while values such as acceptance, solidarity, and civil cooperation are on the decline.

In light of this, we have taken this opportunity to implement a social intervention project to enable students to come together to deal with issues within their community. We decided that makers and technology are key to the learning process in this project.

We consider service learning to be the ideal way to breathe new life into school. The aim is to view it as a key establishment within its community, where local

\footnotetext{
I. Frazzarin $(\bowtie)$

1 IC Zanella, Padua, Italy

D. Leonori

IIS Mattei, Recanati, Italy 
citizens and associations can return to the social dimension of learning, improve their relational skills and foster a sense of community.

Just as important as disciplinary skills are 21 st-century skills, such as creativity critical thinking, collaboration, cooperation, and communication, which can all be strengthened. As Fiorin argues "[...] Strongly rooted in the experience of both the students and the social context, service learning enhances the value of the students' protagonism, and employs the best active and socio-constructive methodologies"1 [2].

Added to this is the impact of the maker approach. As Donaldson argues "learning happens best when learners construct their understanding through a process of constructing things to share with others" [3].

\section{Service Learning, Coding and Digital Storytelling: A Methodological Proposal}

Service learning began as a teaching and learning strategy that connects academic curricula to community problem-solving. It was originally intended for university students, but today's participants are usually elementary, middle, high, and postsecondary schools, with the backing of the Italian Ministry of Education, University and Research and the "Avanguardie educative-INDIRE" movement [4].

It is an approach that teaches students how to think rather than what to think $[5,6]$.

Service learning projects are problem-based. Students or participants learn and develop through active participation, which eventually leads to civic engagement, thereby meeting needs within a community. It is also part of a school's curriculum, enhancing and building upon the students' knowledge and key skills.

Project-based learning is a comprehensive perspective whose goal is to engage students in investigation. Within this framework, students seek solutions to nontrivial problems by "asking and refining questions, debating ideas, making predictions, designing plans and/or experiments, collecting and analyzing data, drawing conclusions, communicating their ideas and findings to others, asking new questions, and creating artifacts" [7].

\section{The Maker Movement Approach and Coding}

Our project was introduced at Istituto Mattei, a secondary school in Recanati, at the beginning of 2019, and will probably continue for the next two years.

During this first year, 100 students ranging from 16 to 18 years will take part in the project. Our students are active participants, in keeping with the maker approach, and they will develop team working skills that will enable them to come up with

\footnotetext{
${ }^{1}$ Own translation.
} 
creative solutions to real-life problems affecting the entire school initially, and then the entire community.

They will create an app, drawing on a range of traditional construction materials, as is usual in maker pedagogy, but also embracing the unique properties of digital tools [8].

The project is in two phases:

- Phase 1: the "Welcome" app prototype

- Phase 2: the "Welcome" app.

\subsection{Phase 1: "Welcome" App Prototype}

The prototype will be developed by first-year students to deal with the main problem in their school community: finding your way around the building. The prototype can include functions specific to the school, which has a maze-like structure that is easy to get lost in, and it can be hard to find the right classroom. It also has many labs; and it would be useful for "school consumers" or new students to have information about the school's amenities, places and rules. The year 11 students will use free tools like Unity $3 \mathrm{~d}$ and $\mathrm{C \#}$ coding language, whereas older students will be introduced to Android coding.

The experiment focuses on the Think, Make, Improve (TMI) cycle, an adaptive decision-making process. This method helps teachers to design their lesson structure and students to understand the process and organize their work. Students will apply the principles of adapting, designing and creating [9], to get into a maker mindset, and increase their learning activities and learning outcomes.

By "adapting" we mean the freedom to use a technology for new purposes. For example, the Unity $3 \mathrm{~d}$ software is normally used for video games, whereas in our project, students create a virtual school with it to help newcomers find their way around the school.

As students designing and creating software, we believe they will apply their skills in cooperation with others, and come up with different solutions, which they can also combine.

Throughout the process, students will be exposed to the "learning by doing" method, coding, and project- based and problem-based learning.

\subsection{Phase 2: The "Welcome" App}

In the second year, the same students will manage the Welcome app for the local community, and will coach new students during its development. They will be expected to give their new colleagues useful advice about the coding process and also about the learning path they themselves have already been on. 
Students are divided into heterogeneous groups based on the needs of the community and will create a geolocation-based app that operates as a virtual tour guide to help Italian and foreign members of the community. Functions will include identifying available resources in their area, historical events, nearby institutions and the customs of foreign citizens.

Users have access to a lot of information, thanks to AR (augmented reality) technology. By scanning a retailer's door, they might see a video interview pop up or the rules of a public place, or information about future events.

The app will need to be multilingual (right from the start screen), to encourage maximum inclusion. Italian will always be the language spoken in videos, but there will be subtitles in several other languages.

The students will interview foreign and Italian retailers in their neighborhoods, as well as local elderly residents, and will record their stories about migration and life in general. The video clips from these interviews will be geo-localized and shared through a child-friendly app called Storymap. The aim of sharing these videos on the neighborhood's social media pages and the school website is to increase local awareness and gather useful feedback.

Maintaining an open communication channel with the community is fundamental to understanding and bringing all those involved closer together on a deeper personal level. According to Bruner, in "the analysis of the stories we tell about our lives: our "autobiographies [...] In the end, we become the autobiographical narratives by which we 'tell about' our lives" [10].

Thus, by working on the prototype first and then on the Welcome app itself, students will take part in peer-to-peer teaching and will be able to deal with small failures by identifying and correcting errors.

\section{Objectives}

The learning objectives we have set will be adapted for the different classes involved in the project. These are: service learning objectives and curricular objectives.

\subsection{Service Learning Objectives for Students}

These objectives will be differentiated depending on what grade the students are in. Overall we can summarize them as follows:

- A better understanding of the circumstances of immigrants and refugees;

- Seeing the point of view of foreigners, and also that of Italian residents; finding similarities between the migration stories told within the communities;

- Devoting "free" time to serving the community; 
- Helping immigrants and refugees learn the Italian language and culture for everyday and more immediate uses.

\subsection{Curricular Objectives and Key Competences}

The following objectives were planned for a secondary school, although they could be used at and adapted to different school levels: history, economics and law: studying the history of migration flows towards Europe and Italy:

- Italian language: exploring linguistic and grammatical aspects of their own language

- Mathematics and science: reprocessing the data collected from Institutional websites

- ICT: learning coding languages

- Foreign languages: using a foreign language as a medium for translation and communication

- Creating digital artifacts (transferable skills).

- Citizenship skills

\subsection{Expected Results}

Service learning enhances 21 st-century skills, and the project's results are expected to have an impact on the students' cognitive and emotional development.

- Learning skills through the maker approach;

- Critical thinking/problem-solving: to create their digital artifact, students will have to resolve an ongoing problem in their community;

- Creativity: demonstrating and expressing themselves creatively (thinking outside the box) by making a video, an app and suitable graphics to go into it;

- Communication: improving communication skills by meeting with, listening to and interviewing their school peers;

- Collaboration: this is an important life skill which can be cultivated by learning to collaborate with others and reaching an objective as a group;

- Literacy skills;

- Information literacy: students will collect and understand data, facts and statistics. Before any information can be used, students will be asked to check the data, facts and stories they have collected;

Technology literacy: thanks to their thorough understanding of today's technology, students will be capable of choosing the best (virtual or physical) tools to complete the task in hand. 


\section{Conclusion}

As Canuto says, projects in service learning offer multiple opportunities to receive positive input, to practice a foreign language through authentic and meaningful interactions, to reflect and become aware of one's own identity and culture, and to appreciate the linguistic and cultural differences of others [11]. In short, it develops the intercultural abilities required in the eight key competences of the European Framework of Reference.

The main feature of service learning is working on social solidarity projects/actions that are not disconnected from school learning; rather, they are fully integrated into the curriculum, and thus help improve the well-being of the class.

Many service-learning-type projects have been tested in Italy since the setup of the SL (service learning) Working Group, approved by the Head of Education of the Ministry of Education, University and Research, which was formalized in November 2016, with the participation of three Regions (Calabria, Lombardy, Tuscany). The most recent ScAR (Scuola Attiva Risorse) project was based on the synergy between the Polytechnic University of Milan, schools in the Milan area, the Municipality of Milan and other public and private institutions [12].

The National Digital School Plan [13] also emphasizes the importance of advanced heritage education and suggests that all students should be offered an opportunity to experience the digital management of cultural heritage. Moreover, European policies [14] acknowledge the right of every citizen to access and participate freely in cultural life.

Given the experiences mentioned above, we hope service learning will also be tested in our communities to enable further research, experimentation and dissemination in this area.

\section{References}

1. Charles, L., Rankin, W., Speight, C.: Education, knowledge, and learning-an overview of research and theory about constructionism and making. PI-TOP 8 (2019)

2. Fiorin, I.: Oltre l'aula. La pedagogia del Service Learning, Mondadori (2016)

3. Donaldson, J.: The maker movement and the rebirth of constructionism. Hybrid Pedagogy. http://www.hybridpedagogy.com/journal/constructionism-reborn/

4. INDIRE: Avanguardie educative. http://innovazione.indire.it/avanguardieeducative/servicelearning

5. Harris, J.D: Service-Learning and the Liberal Arts: How and Why it Works, pp. 21-39. Lexington Books (2011); Miettinen (2000)

6. Miettinen, R.: The concept of experiential learning and John Dewey's theory of reflective thought and action. Int. J. Lifelong Educ. 54-72 (2000)

7. Blumenfeld, P., Soloway, E., Marx, R., Krajcik, J., Guzdial, M., Palincsar, A.: Motivating project based learning: sustaining the doing, supporting the learning. Educ. Psychol. 26, 369-398 (1991)

8. International Conference, the Future of Education 7th Edition, Florence, Italy Conference Proceeding by Pixel 
9. Bullock, S.M., Sator, A.J.: Maker pedagogy and science teacher education. J. Can. Assoc. Curriculum Stud. 13, 60-87 (2015)

10. Bruner, J: Life as narrative. Soc Res 71(3) 691-710 (2004). https://ewasteschools.pbworks. com/f/Bruner_J_LifeAsNarrative.pdf

11. Canuto, L: Service learning: dai fondamenti teorici ai benefici per lo studente di lingua straniera. Univ. Br. Columbia 5(2) (2016)

12. http://www.scar.polimi.it/wp-content/uploads/2018/11/Progetto-ScAR-sintesi.pdf

13. https://www.miur.gov.it/innovazione-digitale

14. The Faro Convention or the Council of Europe Framework Convention on the Value of Cultural Heritage for Society (2005)

Open Access This chapter is licensed under the terms of the Creative Commons Attribution 4.0 International License (http://creativecommons.org/licenses/by/4.0/), which permits use, sharing, adaptation, distribution and reproduction in any medium or format, as long as you give appropriate credit to the original author(s) and the source, provide a link to the Creative Commons license and indicate if changes were made.

The images or other third party material in this chapter are included in the chapter's Creative Commons license, unless indicated otherwise in a credit line to the material. If material is not included in the chapter's Creative Commons license and your intended use is not permitted by statutory regulation or exceeds the permitted use, you will need to obtain permission directly from the copyright holder. 